\title{
The Plasticity of Root Systems in Response to External Phosphate
}

\author{
Guoqiang Huang ${ }^{1}$ and Dabing Zhang ${ }^{1,2, *}$ \\ 1 Joint International Research Laboratory of Metabolic \& Developmental Sciences, SJTU-University of \\ Adelaide Joint Centre for Agriculture and Health, School of Life Sciences and Biotechnology, \\ Shanghai Jiao Tong University, Shanghai 200240, China; huang19880901@126.com \\ 2 School of Agriculture, University of Adelaide-SJTU Joint Centre for Agriculture and Health, Food and Wine, \\ University of Adelaide, Waite Campus, Urrbrae 5064, South Australia \\ * Correspondence: zhangdb@sjtu.edu.cn
}

Received: 29 June 2020; Accepted: 27 July 2020; Published: 19 August 2020

check for updates

\begin{abstract}
Phosphate is an essential macro-element for plant growth accumulated in the topsoil. The improvement of phosphate uptake efficiency via manually manipulating root system architecture is of vital agronomic importance. This review discusses the molecular mechanisms of root patterning in response to external phosphate availability, which could be applied on the alleviation of phosphate-starvation stress. During the long time evolution, plants have formed sophisticated mechanisms to adapt to environmental phosphate conditions. In terms of root systems, plants would adjust their root system architecture via the regulation of the length of primary root, the length/density of lateral root and root hair and crown root growth angle to cope with different phosphate conditions. Finally, plants develop shallow or deep root system in low or high phosphate conditions, respectively. The plasticity of root system architecture responds to the local phosphate concentrations and this response was regulated by actin filaments, post-translational modification and phytohormones such as auxin, ethylene and cytokinin. This review summarizes the recent progress of adaptive response to external phosphate with focus on integrated physiological, cellular and molecular signaling transduction in rice and Arabidopsis.
\end{abstract}

Keywords: phosphate; root system architecture; Arabidopsis; rice

\section{Introduction}

Phosphate is an macroelement required for almost all biologic activities of plants, such as photosynthesis, nitrogen fixation, carbohydrate metabolism, energy generation, nucleic acid synthesis, enzyme activation/inactivation, signaling transduction [1]. Phosphate starvation causes extensive losses to agricultural production by impairing plant growth and reducing yield [2]. By estimation, more than 30\% world's arable land has insufficient available phosphate required for crop growth [2]. At the current rate of consumption, the finite and non-renewable natural resources of inexpensive phosphate may be depleted before 2050 [2-5]. Nevertheless, the efficiency of phosphate uptake by crop root system is still below $25 \%$ due to the accumulation of phosphate at the topsoil in many natural and agricultural ecosystems [5,6]. In addition, excessive phosphate has been applied for the arable farming system and then discharged into the environment, resulting in severe water pollution [7]. Therefore, the improvement of phosphate uptake efficiency is critical for the reduction of fertilizer input, achieving the environmentally sustainable agriculture [8].

On the other hand, to overcome phosphate deficiency, plants have evolved various adaptive mechanisms to improve the efficiency of phosphate uptake [9]. Root system architecture is highly plastic in response to various phosphate conditions by modulating the length of primary root 
and length/density of lateral root, root hair and crown root angle [8,10-15]. Dicot plants such as Arabidopsis thaliana has the tap root system with the dominant primary root and branches consisting of secondary, smaller lateral roots and root hairs [15] (Figure 1). While monocot plants, such as rice (Oryza sativa), wheat (Triticum aestivum) and maize (Zea mays) develop fibrous root systems mainly consisting of adventitious roots (or called crown roots in cereals) [15] (Figure 1). For rice, adventitious roots are mainly formed from postembryonic shoot-borne roots, and primary and crown roots have the capacity to branch by forming lateral roots and generating root hairs from their epidermal cells. Given that different root system morphologies were gradually formed during the evolution for the two species. Arabidopsis and rice have developed distinct mechanisms to enhance topsoil-exploring abilities under low phosphate conditions. Shallow root system was formed through reducing primary-root length, increasing root hair/lateral root density/length in Arabidopsis under low phosphate conditions. Unlike that of Arabidopsis, rice would develop this system mainly via increasing crown-root growth angle and root hair length to cope with low phosphate conditions (Figure 1).

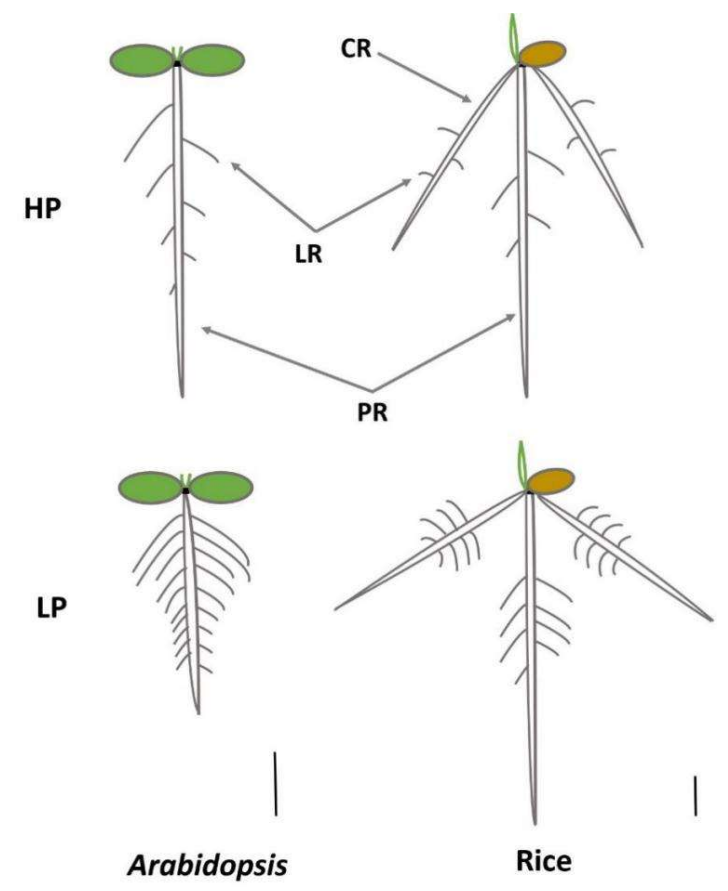

Figure 1. Schematic representation of a typical allorhizic (left) and secondary homorhizi (right) root system grown in HP (upper) and LP (lower), exemplified by Arabidopsis and rice. Shallow and deep root systems were formed in LP or HP, respectively. Shorter PR length, longer length and higher density of LR and root hair were formed for Arabidopsis in LP; Larger CR growth angle and longer length and higher density of root hair were developed for rice in LP. PR - primary root; LR-lateral root; $\mathrm{CR}$-crown root; HP—high phosphate conditions; LP—low phosphate conditions. Scale bars, $1 \mathrm{~cm}$.

Researchers have created artificial system with adding or reducing the exogenous phosphate (without changing chloride concentration) to mimick the high or low phosphate conditions (rather than chloride toxicity) in the natural environments. Through genetic screening approaches, they have identified a series of regulators modulating root system architecture in response to external phosphate, and these factors have formed a regulatory cascade described in previous review articles $[8,11-14]$. In this review, we focus on the recent understanding in the interplay between phosphate signaling pathways and plant hormones, actin filaments and post-translational modifications in regulating root system architecture of Arabidopsis and rice. 


\section{Root System Architecture Modulated by Phytohormones in Response to External Phosphate}

\subsection{Auxin}

It is well known that auxin regulates root patterning in response to phosphate starvation $[8,11,13,14]$. Exogenous auxin treatment caused the localized architecture alteration of phosphate-adequate roots, mimicking that of roots cultured under low phosphate conditions [16]. Similar to the response of low-phosphate grown root system, the treatment of exogenous auxin caused the increase of Arabidopsis lateral-root density which depends on the auxin receptor TRANSPORT INHIBITOR RESPONSE1 (AtTIR1) and two auxin response factors, AUXIN RESPONSE FACTOR7 (AtARF7) and AtARF19 [17,18]. Furthermore, the promotor of PHOSPHATE STARVATION RESPONSE 1 (AtPHR1) which encodes one MYB transcription factor with the induced expression by phosphate starvation, contains three auxin-response elements that can be directly bound by AtARF7 and AtARF19 to promote its expression under low phosphate conditions [14]. AtPHR1 and OsPHR2 (the rice homolog of Arabidopsis PHR1) play a conserved and central roles in phosphate utilization by regulating phosphate signaling and homeostasis to assist plant adaption to phosphate deficiency by binding to the cis-element with an imperfect palindromic sequence (GnATATnC, i.e., PHR1 binding site [P1BS]) [19-23]. The promotors of PHOSPHATE TRANSPORTER 1 (AtPT1) and OsPT2 encoding phosphate transporters contain P1BS motifs, which can be physically bound by AtPHR1 and OsPHR2, respectively [21,24]. There are 9 and 13 high-affinity PTs in Arabidopsis and rice and accounting for about $70 \%$ of the total root phosphate transport activity $[25,26]$. Besides the PTs, INDUCED BY PHOSPHATE STARVATION1 (IPS1), microRNA399 (miR399) and some phosphate signaling components were also directly regulated by PHR1/OsPHR2 in phosphate uptake, translocation and response $[19,20]$. A systemic framework has been proposed based on the above phosphate-signaling components, which were downstream regulators of AtARF7/19. Therefore, the changes of lateral root density under low phosphate is in an auxin-dependent manner.

Unlike the increasing in density of lateral root under phosphate starvation conditions, the auxin-induced root hair growth under this condition is evolutionarily conserved in Arabidopsis and rice $[8,13]$. Exogenous auxin can increase the length of root hair under high phosphate conditions, but not under low phosphate conditions in both rice and Arabidopsis [8,13]. Without exogenous auxin, aux1 (an auxin influx carrier mutant) showed reduced phosphate uptake and arrested root hair expansion in low phosphate conditions [13]. Targeted expression of AtAUX1 in lateral root cap and epidermal cells can restore root-hair defects under low phosphate [13], demonstrating that low phosphate-induced root-hair elongation requires the mobilization of auxin from root apex to root-hair zone via AUX1 (Figure 2). There are five closely related OsAUX1/LAX genes in rice genome [8]. Among them, only OsAUX1, but not others can complement the defective gravity response of aux1-22 in Arabidopsis, indicating that AUX1 performs a conserved role in the two species [8]. Intriguingly, osaux 1 mutants exhibited shallow root system, but reduced phosphate uptake efficiency owing to shorter root-hair length caused by less auxin response of root epidermal cells under low phosphate conditions [8]. Auxin response in epidermis is elevated as a result of the increased auxin biosynthesis at the root apex under the low external phosphate conditions, and then auxin was mobilized to the root-hair zone in an OsAUX1-dependent manner [8], which is also conserved in Arabidopsis. Moreover, the elevated level of auxin at elongation zone and root hair zone was shown to be caused by the increased expression level of auxin biosynthesis gene TRYPTOPHAN AMINOTRANSFERASE OF ARABIDOPSIS1 (AtTAA1) in the root apex and AUX1-mediated auxin transport [13]. In addition, ROOT HAIR DEFECTIVE 6-LIKE 2 (AtRSL2) and AtRSL4 were upregulated with redundant roles in promoting root-hair elongation when exposed to low phosphate conditions [13]. Therefore, we propose a mechanistic regulatory framework of root-hair elongation mediated by auxin under phosphate-starvation conditions (Figure 2). 


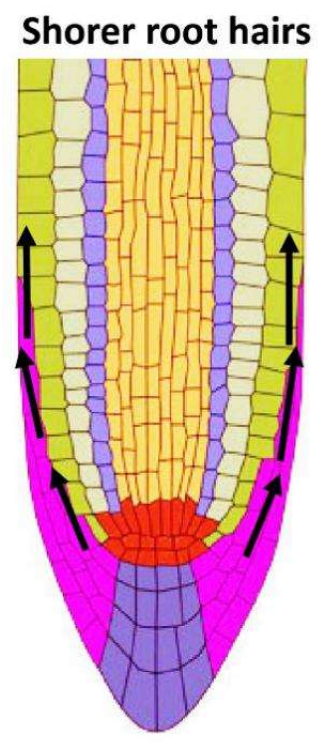

HP

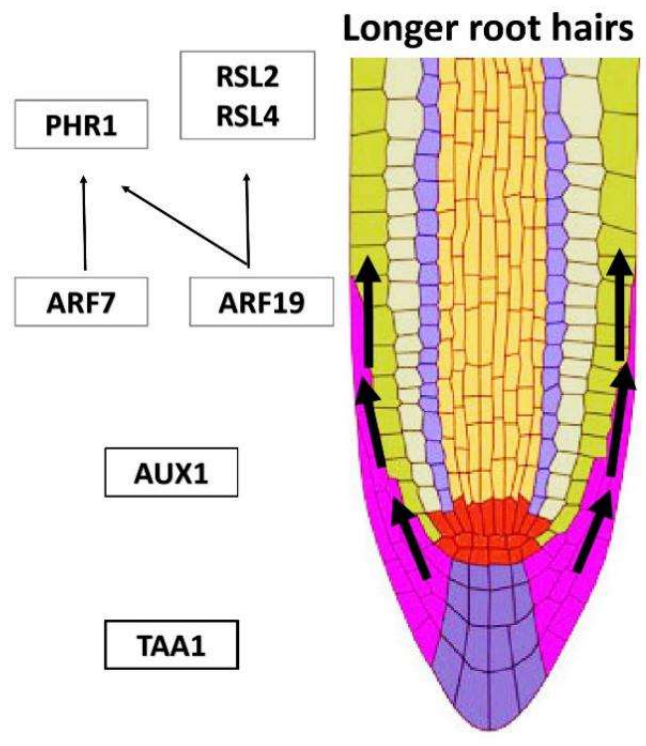

LP

Figure 2. Schematic illustration of root-hair elongation under low phosphate conditions [13,14]. LP elevated the auxin levels of elongation and root-hairs zone by increasing auxin biosynthesis from higher expression of AtTAA1 in root tip and enhanced AUX1-mediated auxin transport through lateral root cap and epidermal cells. The increased auxin levels lead to the induced expression of AtRSL2/4 and AtPHR1 regulated by AtARF7/19 in elongation zone and differentiation zone, finally promoting root-hair elongation. Black arrows indicate the auxin transport rate and direction (left, less auxin transport; right, more auxin transport). $\mathrm{HP} / \mathrm{LP}$ — high/low phosphate conditions.

\subsection{Ethylene}

Several studies have suggested that ethylene functions in modulating root architecture in low phosphate conditions [27-29]. The transcript levels of ethylene biosynthesis genes were upregulated in low phosphate conditions [30]. Moreover, the addition of ethylene precursor 1-aminocyclopropane-1-carboxylic acid (ACC) inhibited primary root growth and lateral root formation in both low- and high-phosphate environments [17]. Yet, the precise roles of ethylene in regulating root adaptions to phosphate availability are still unclear. It appears that ethylene regulates low phosphate-induced root response via changing its biosynthesis and responsiveness [31]. The ETHYLENE OVERPRODUCER 1 (AtETO1) and CONSTITUTIVE TRIPLE RESPONSE 1 (AtCTR1) mutants showed less response to phosphate-starvation conditions [17]. Therefore, both the biosynthesis and responsiveness of ethylene were demonstrated to modulate primary root elongation and lateral root formation in response to external phosphate availability.

The initiation and elongation of root hairs were induced when exposed to more ethylene produced in low phosphate condition [27]. The low phosphate-induced root-hair growth results from the increased number of hair cells and shortening trichoblast cells [27], whilst this phenotype was strongly suppressed in ethylene-insensitive mutants, such as ETHYLENE INSENSITIVE 7 (atein7) and ETHYLENE INSENSITIVE ROOT 1 (ateir1/pin2) [27]. Moreover, several studies reported that both low phosphate conditions and ethylene regulate root elongation via stimulating auxin biosynthesis of root apex and facilitating AUX1-mediated auxin transport along lateral root cap and epidermal cells of meristem and elongation zone [13,32-34]. In addition, OsYUCCA8 (OsYUC8)-mediated auxin biosynthesis genetically acts downstream of OsEIN3-LIKE1 (OsEIL1), which are sufficient for activating the expression of ethylene-response genes required for root phosphate-starvation response [35]. Hence, ethylene is likely utilized to fine-tune the low phosphate-induced adaptations of root system in an auxin-dependent manner. 


\subsection{Cytokinin}

Cytokinin is proved to play positive and negative roles in shoot and root growth, respectively [36]. The activity of root apical meristem was inhibited by exogenous cytokinin, causing a reduction of low-phosphate response [37]. Moreover, the expression of INDUCED BY PHOSPHATE STARVATION 1 (AtIPS1) and other phosphate-starvation response genes were repressed with the treatment of cytokinin in Arabidopsis [38]. In turn, low phosphate represses cytokinin responsiveness and sensitivity through reducing its concentrations [39] and decreasing the expression of CYTOKININ RESPONSE 1 (AtCRE1) (a cytokinin receptor) [40]. Thus, an antagonistic relationship was believed to exist between cytokinin and phosphate starvation signaling.

However, the changes of cytokinin signaling triggered by low phosphate are the second response, as a consequence of "crosstalk" between auxin and phosphate signaling cascades [41]. It is reported that cytokinin biosynthesis via isopentenyladenosine- $5^{\prime}$-monophosphate-independent pathway was suppressed by auxin in a fast way [41]. In turn, cytokinin perturbs the expression of auxin efflux carriers PINs and disturbs the pattern of lateral root primordia via preventing the formation of auxin gradient [42]. These findings demonstrate that auxin and cytokinin play opposite effects in lateral root formation induced by low phosphate conditions.

Besides the above phytohormones, brassinosteroid (BR) was also proved to regulate root morphology in low phosphate conditions [43]. Transcription factor BRI1-EMS-SUPPRESSOR 1 (AtBES1) in BR signaling pathways is essential for maintaining normal root morphology under phosphate starvation conditions [43]. Despite that some functions of phytohormones in low phosphate response have been uncovered, and more potential roles await to be revealed.

\section{The Roles of Actin Filaments in Crown-Root Angle Adjustment}

Crown roots are major components of rice root system and their growth angle determines the phosphate uptake efficiency [44]. To survive in many natural and agricultural ecosystems with limited phosphate resource in the topsoil $[45,46]$, crops such as rice has to increase phosphate uptake efficiency at minimum cost through increasing their crown-root growth angle to enlarge the exploring area within the topsoil $[47,48]$. Rice MORPHOLOGY DETERMINANT (RMD) is a type II formin homology 5 (OsFH5) and regulates the dynamics of actin filaments [49]. RMD is localized on the outer membrane of chloroplast or statolith within leaf epidermal or root columella cells, and acts as a scaffold protein to directly link actin filaments and chloroplasts/statoliths, respectively [11,50] (Figure 3). Loss-of-function mutants of $R M D$ exhibited an enhanced gravitropic response due to rapider statoliths movement in root tip [11]. Moreover, the expression level of $R M D$ was negatively correlated with the external phosphate availability, and RMD is key to the transition between deep and shallow root systems under high- and low-phosphate conditions, respectively (Figure 3) [11]. In high phosphate conditions, the transcript level of $R M D$ was downregulated, causing less ring-like actin filaments surrounding statoliths, quicker movement of statoliths and enhanced gravity-sensing process and finally forming deep root systems (Figure 3) [11]. On the contrary, low-phosphate conditions induced the expression of RMD and more ring-like actin filaments around statoliths slow down the sedimentation of statoliths and gravity-sensing process, ultimately causing shallow root system (Figure 3) [11]. Therefore, RMD appears to function in buffering gravity-sensing process responding to external phosphate levels, which provides new mechanistic insights into how plants regulate key components of gravitropic machinery to adapt their root-systems architecture to soil phosphate availability (Figure 3) [11]. Meanwhile, the extent to which upregulation of $R M D$ at the transcript level is responsible for this action needs more investigation [11]. For instance, the transcription factors that modulate the expression level of $R M D$ remain to be elucidated to clarify the molecular mechanisms of adaptive response to external phosphate (Figure 3). Moreover, RMD acts as a scaffold protein and its interactors are vital to uncover the regulatory mechanisms of RMD at the protein level (Figure 3). In addition, there are another 15 formin members in rice genome and their roles in the adaptive response to other environmental cues are fascinating and remain to be investigated in future. 


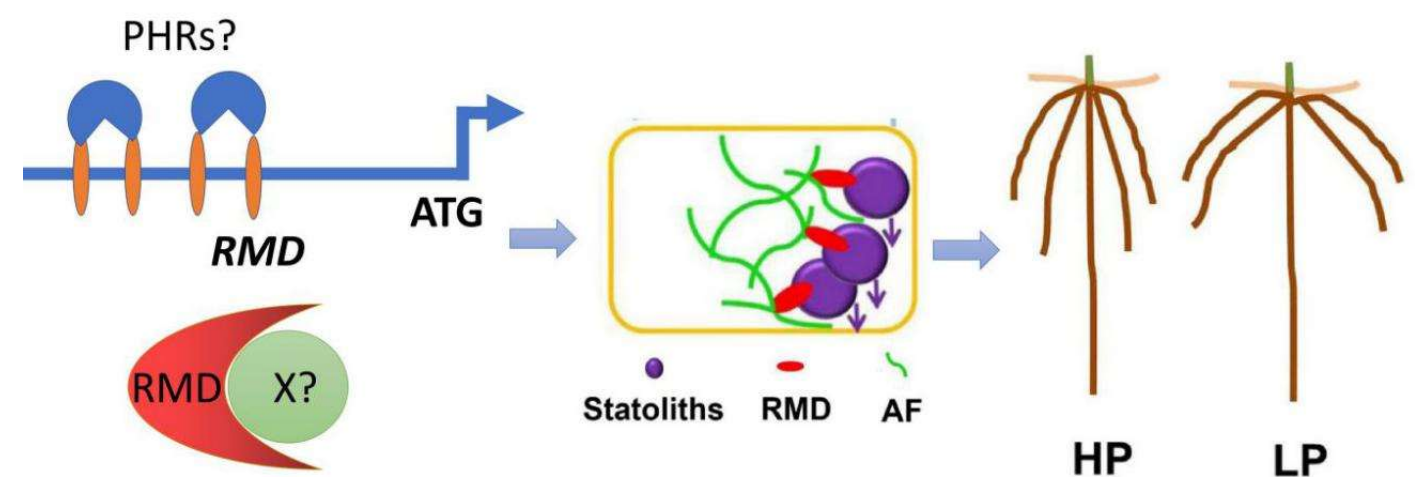

Figure 3. Proposed model for phosphate-dependent RMD-mediated regulation of RSA [12]. RMD links statoliths and actin filaments (AFs) in root columella cells, which is essential for RSA adaptation to different phosphorus conditions through fine-tuning gravitropism. RMD links statoliths and AFs in root columella cells which is essential for RSA adaptation to different phosphate conditions through fine-tuning gravitropism. There are 4 PHR1-like motifs among RMD promotor and which likely to be physically bound and activated by PHRs in rice. RMD-interacting proteins were necessary to elucidate the underlying mechanism in this response. In $\mathrm{HP}$, the expression of $R M D$ is lower, gravity-sensing process is enhanced and deep root system was shaped. In LP, the expression of RMD is higher, gravity-sensing process is dampened and shallow root system was developed.

\section{Post-Translational Modification in Phosphate Signaling}

As a more precise mechanism, post-translational regulation such as ubiquitination and SUMOylation (small ubiquitin-like modifier peptide is attached to protein) in phosphate starvation response has been well studied [51,52]. SUMOylation alters protein activity, subcellular localization or the ability of interaction instead of triggering their targets degradation through $26 \mathrm{~S}$ proteasome or vacuole, conventionally discovered in ubiquitination [53]. Here we briefly summarize the mechanisms of the two post-translational modifications in affecting phosphate uptake, long-distance phosphate signaling and phosphate starvation responses.

\subsection{Ubiquitination}

Ubiquitin $(\mathrm{Ub})$ is a small peptide and covalently linked to lysine residues of targeted proteins through specific enzymatic cascades, which began by transferring a $\mathrm{Ub}$ moiety from an $\mathrm{E} 1 \mathrm{Ub}$-activating enzyme (E1) to an E2 Ub-conjugating enzyme (E2). Then, E3 Ub-ligases (E3) brings together the E2 and the targets which were then ubiquitinated [54]. After several cycles of ubiquitination, the targets were polyubiquitinated and subsequently recognized by the $26 \mathrm{~S}$ proteasome or vacuole for degradation, which depends on the way of ubiquitin linkage [54]. Low phosphate conditions accelerate the degradation of AUXIN/INDOLE-3-ACETIC ACID (AtAUX/IAA), thereby unshackling AtARF19 that activates the expression of AtPHR1 [14,18]. Phosphate-starvation mediated root-system-architecture remodeling partially depends on the AtPIN2 accumulation through lysine ${ }^{63}$-linked plasma membrane (PM) cargo ubiquitylation [55,56]. Moreover, active PTs were relocated on the PM to increase phosphate uptake, by contrast, the PM-accumulated PTs were degraded in phosphate-sufficient conditions [23,57]. The proteins of AtPT1-4 were accumulated in the knockout mutants of PHOPSHATE 2 (AtPHO2), which encodes an endosome-localized E2 ubiquitin-conjugating enzyme [58]. The RING-type E3 ligase NITROGEN LIMITATION ADAPTATION 1 (NLA1) was reported to interact with PTs and target their degradation and nla1 has a higher phosphate contents conserved in Arabidopsis and rice $[23,59]$. In addition, the transcriptional activities of PHRs are negatively regulated solely by SYG/Pho81/XPR1 (SPX) domain-containing proteins (SPXs), which could interact with PHRs and inhibit their binding ability to P1BS motifs under high phosphate conditions that is conserved in Arabidopsis and rice [60,61]. However, the RING-type E3 ligases OsSDEL1 and OsSDEL2 (SPX4 degradation E3 ligases 1 and 2) interact with OsSPX4, causing its degradation and the liberation of OsPHR2 in 
phosphate starvation conditions [60,61] (Figure 4). The ubiquitination-mediated regulation of SPX4 deepens our understanding on the phosphate signaling cascade.
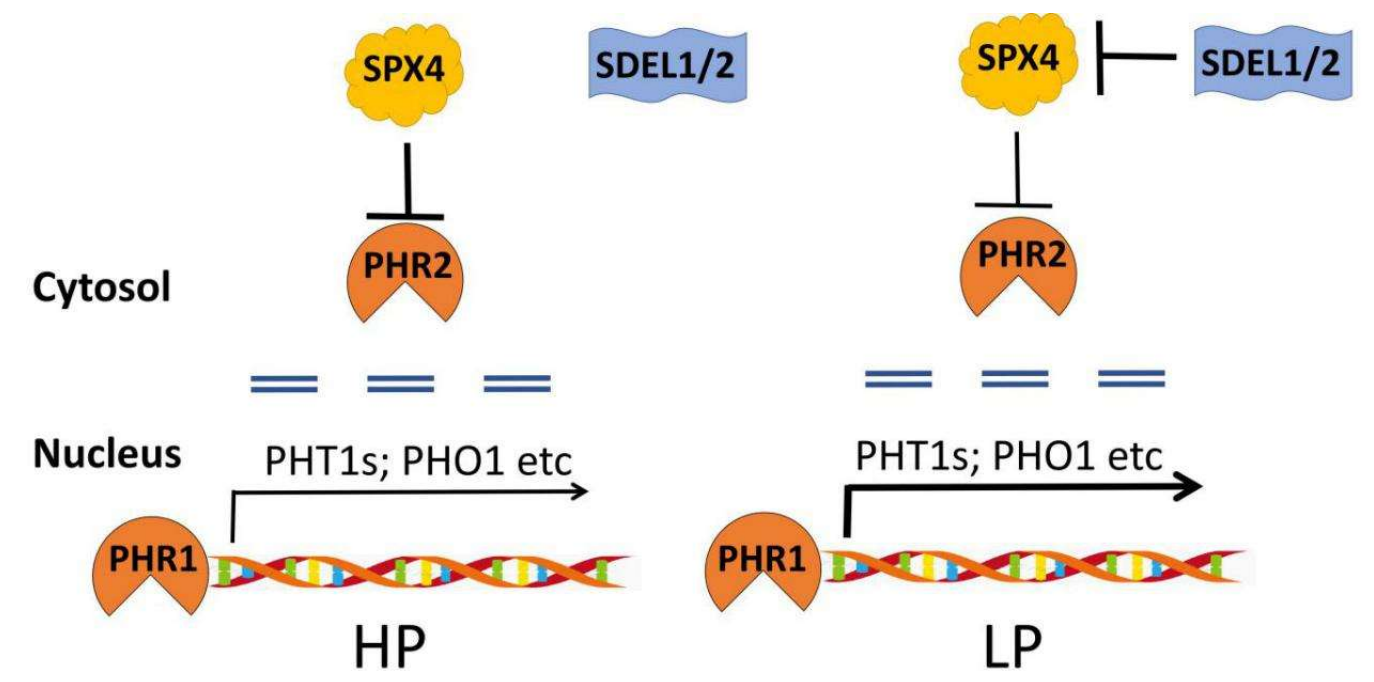

Figure 4. Ubiquitination-mediated translational regulation of the phosphate starvation response [60,61]. In high phosphate conditions, OsSPX4 interacts with OsPHR2, and reduces its ability to bind P1BS motifs and activate the expression of downstream regulators. In low phosphate conditions, OsSDEL1/2 competes with OsPHR2 to interact with OsSPX4, resulting in the degradation of OsSPX4 and the liberation of OsPHR2. OsPHR2 is translocated into the nucleus, which activates the expression of the downstream genes. Double horizontal dotted lines mean the nuclear membrane. The thickness of black arrows indicate the transcriptional activation level.

\subsection{SUMOylation}

SUMO is an $~ 100$-amino-acid polypeptide and SUMOylation is a reversible process erased by deSUMOylating proteases (DSPs) that specifically cleave the isopeptide linkage between SUMO and the targets [62]. Recent studies demonstrated that plant SUMOylation plays vital roles in phosphate starvation response [63]. The SUMO E3 ligase SAP and Miz1 (AtSIZ1) regulates root patterning under phosphate starvation [63] and siz1 exhibits reduced length of primary root and increased lateral root proliferation in phosphate-insufficient conditions [63]. Low Phosphate Root1 (AtLPR1) and AtLPR2 were respectively SUMOylated by AtSIZ1 and another SUMO ligase METHYL METHANE SULFONATE SENSITIVITY 21 (AtMMS21), which regulate local phosphate sensing in phosphate-starvation response [64,65]. Purple acid phosphatase 10 (AtPAP10) and AtPAP26 were responsible for internal phosphate recycling or releasing phosphate from external organophosphates for plant uptake in phosphate-deprivation conditions [66,67]. AtPAP10/26, AtARF7 and AtPHR1 could also be SUMOylated $[63,66,67]$, while whether these processes affect their function in response to phosphate starvation requires further study. As an emerging post-translational modification in plants, more SUMOylation targets and their roles need to be identified in phosphate signaling pathway.

Overall, recent studies have addressed the significant roles of post-translational modifications, which regulate phosphate-starvation response at morphologic, physiological, biochemical and molecular levels. Despite some progresses have been made, many interesting questions remain to be answered on how plants employ post-translational modification for a higher phosphate-uptake efficiency.

\section{Conclusions and Future Perspectives}

Based on previous studies and the above discussion, the molecular mechanisms of the adaptive response of root system to external phosphate has been well described [11-13]. Low phosphate availability alters the local concentrations, transport or sensitivity of intracellular components and 
subsequently modulates the expression level of the downstream genes that control the initiation, adjustment and maintenance of root system development. Some progresses have been achieved to open inroads to understand the mechanisms of phosphate sensing and response. Root cap was demonstrated to perform the roles to sense and/or response to low concentrations of environmental phosphate by split root experiments in Arabidopsis [13,50]. Therefore, the functional analysis of the different root tissues of the root tip will be crucial to identify the early steps of these process. In addition, how external phosphate is sensed by plants is always a fascinating subject that deserved to be more investigation.

As a macro-element, phosphate is easily accumulated in the topsoil [1]. Regarding this, shallow root system have advantages in absorbing limited phosphate from the topsoil [11]. Previous works were mainly focus on the local architectures of root system, such as primary root length, the length/density of lateral root/root hair and crown root growth angle [10-15]. However, the formation of shallow root system requires coordinated activities of different-type roots. For Arabidopsis, many studies have uncovered that the regulatory mechanism of root system in response to external phosphate. Compared with that of Arabidopsis, the reported studies were mainly focus on the length of primary/crown root in rice [26,59-61]. Crown root growth angle as an agronomic architecture determining the transition between shallow and deep root system was less investigated. RMD is type II formin (FH5), regulates the dynamics of actin filaments and involves the transition between shallow and deep root systems [11]. The post-transcriptional and post-translational modification of RMD, which is vital to uncover its regulatory mechanisms, should be elucidated in further work. Moreover, RMD-like proteins that regulate root system architecture responding to external phosphate are worth more attention. In addition, a perfect shallow root system (not local changes) is necessary to help plants perform better (especially high yield) in low phosphate conditions, and reduce the use of phosphate fertilization, and promote the development of sustainable agriculture.

Phosphate shortage is becoming severely urgent associated with the increasing demands created by human activities $[3,5]$. This has caused disadvantageous impacts on the fundamental processes of plants growth and production and finally bringing great damage to global agriculture and food security [3]. The improvement for crop yield-stability dealing with low phosphate stress has been partially accomplished via human-selection breeding through natural genetic variations [3,5]. Further, genetic engineering of plants for higher phosphate-uptake efficiency may have far-reaching effects to improve phosphate starvation tolerance. The public availability of genetic variations (e.g., 3010 diverse Asian culture rice) provides an invaluable resource for rice genomic research and breeding [68]. To examine the associations of genetic variations with agronomic traits (not only root system traits) under low phosphate conditions is of paramount importance to guide and accelerate rice breeding of sustainable agriculture.

Author Contributions: G.H. drafted the manuscript and designed figures. D.Z. edited and commented on the manuscript and figures. All authors have read and agreed to the published version of the manuscript.

Funding: This work was funded by the National Key Technologies Research and Development Program of China, Ministry of Science and Technology (Grant Numbers 2016YFD 0100804 and 2016YFE0101000), the National Natural Science Foundation of China (grant nos. 31970803, 31861163002), China Postdoctoral Science Foundation funded project (2019M661486) and Shanghai Post-doctoral Excellent Program (2018063).

Conflicts of Interest: The authors declare no conflict of interest.

\section{References}

1. Niu, Y.F.; Chai, R.S.; Jin, G.L.; Wang, H.; Tang, C.X.; Zhang, Y.S. Responses of root architecture development to low phosphorus availability: A review. Ann. Bot. 2013, 112, 391-408. [CrossRef]

2. Mittler, R. Abiotic stress, the field environment and stress combination. Trends Plant Sci. 2006, 11, 15-19. [CrossRef]

3. Mickelbart, M.V.; Hasegawa, P.M.; Bailey-Serres, J. Genetic mechanisms of abiotic stress tolerance that translate to crop yield stability. Nat. Rev. Genet. 2015, 16, 237-251. [CrossRef] [PubMed] 
4. Cooper, J.; Lombardi, R.; Boardman, D.; Carliell-Marquet, C. The future distribution and production of global phosphate rock reserves. Resour. Conserv. Recycl. 2011, 57, 78-86. [CrossRef]

5. Vance, C.P.; Uhde-Stone, C.; Allan, D.L. Phosphorus acquisition and use: Critical adaptations by plants for securing a nonrenewable resource. New Phytol. 2003, 157, 423-447. [CrossRef]

6. Tiessen, H. Phosphorus in the global environment. In The Ecophysiology of Plant-Phosphorus Interactions; Springer: Dordrecht, The Netherlands, 2008; pp. 1-7.

7. Chen, M.; Chen, J.; Sun, F. Agricultural phosphorus flow and its environmental impacts in China. Sci. Total Environ. 2008, 405, 140-152. [CrossRef] [PubMed]

8. Giri, J.; Bhosale, R.; Huang, G.; Pandey, B.K.; Parker, H.; Zappala, S.; Yang, J.; Dievart, A.; Bureau, C.; Ljung, K.; et al. Rice auxin influx carrier OsAUX1 facilitates root hair elongation in response to low external phosphate. Nat. Commun. 2018, 9, 1408. [CrossRef] [PubMed]

9. Masson, P.H.; Tasaka, M.; Morita, M.T.; Guan, C.; Chen, R.; Boonsirichai, K. Arabidopsis thaliana: A model for the study of root and shoot gravitropism. Arab. Book 2002, 1, e0043. [CrossRef]

10. Tyburski, J.; Dunajska-Ordak, K.; Skorupa, M.; Tretyn, A. Role of ascorbate in the regulation of the Arabidopsis thaliana root growth by phosphate availability. J. Bot. 2012, 2012, 580342. [CrossRef]

11. Huang, G.; Liang, W.; Sturrock, C.J.; Pandey, B.K.; Giri, J.; Mairhofer, S.; Wang, D.; Muller, L.; Tan, H.; York, L.M.; et al. Rice actin binding protein RMD controls crown root angle in response to external phosphate. Nat. Commun. 2018, 9, 2346. [CrossRef]

12. Huang, G.Q.; Li, E.; Ge, F.R.; Li, S.; Wang, Q.; Zhang, C.Q.; Zhang, Y. Arabidopsis RopGEF4 and RopGEF10 are important for FERONIA-mediated developmental but not environmental regulation of root hair growth. New Phytol. 2013, 200, 1089-1101. [CrossRef] [PubMed]

13. Bhosale, R.; Giri, J.; Pandey, B.K.; Giehl, R.F.H.; Hartmann, A.; Traini, R.; Truskina, J.; Leftley, N.; Hanlon, M.; Swarup, K.; et al. A mechanistic framework for auxin dependent Arabidopsis root hair elongation to low external phosphate. Nat. Commun. 2018, 9, 1409. [CrossRef] [PubMed]

14. Huang, K.L.; Ma, G.J.; Zhang, M.L.; Xiong, H.; Wu, H.; Zhao, C.Z.; Liu, C.S.; Jia, H.X.; Chen, L.; Kjorven, J.O.; et al. The ARF7 and ARF19 transcription factors positively regulate PHOSPHATE STARVATION RESPONSE1 in Arabidopsis roots. Plant Physiol. 2018, 178, 413-427. [CrossRef] [PubMed]

15. Meng, F.; Xiang, D.; Zhu, J.; Li, Y.; Mao, C. Molecular mechanisms of root development in rice. Rice (N. Y.) 2019, 12, 1-10. [CrossRef]

16. Gilbert, G.A.; Knight, J.D.; Vance, C.P.; Allan, D.L. Proteoid root development of phosphorus deficient lupin is mimicked by auxin and phosphonate. Ann. Bot.—Lond. 2000, 85, 921-928. [CrossRef]

17. Lopez-Bucio, J.; Hernandez-Abreu, E.; Sanchez-Calderon, L.; Nieto-Jacobo, M.F.; Simpson, J.; Herrera-Estrella, L. Phosphate availability alters architecture and causes changes in hormone sensitivity in the Arabidopsis root system. Plant Physiol. 2002, 129, 244-256. [CrossRef]

18. Perez-Torres, C.A.; Lopez-Bucio, J.; Cruz-Ramirez, A.; Ibarra-Laclette, E.; Dharmasiri, S.; Estelle, M.; Herrera-Estrella, L. Phosphate availability alters lateral root development in Arabidopsis by modulating auxin sensitivity via a mechanism involving the TIR1 auxin receptor. Plant Cell 2008, 20, 3258-3272. [CrossRef]

19. Bari, R.; Datt Pant, B.; Stitt, M.; Scheible, W.R. PHO2, microRNA399, and PHR1 define a phosphate-signaling pathway in plants. Plant Physiol. 2006, 141, 988-999. [CrossRef]

20. Rubio, V.; Linhares, F.; Solano, R.; Martin, A.C.; Iglesias, J.; Leyva, A.; Paz-Ares, J. A conserved MYB transcription factor involved in phosphate starvation signaling both in vascular plants and in unicellular algae. Genes Dev. 2001, 15, 2122-2133. [CrossRef]

21. Zhou, J.; Jiao, F.C.; Wu, Z.C.; Li, Y.Y.; Wang, X.M.; He, X.W.; Zhong, W.Q.; Wu, P. OsPHR2 is involved in phosphate-starvation signaling and excessive phosphate accumulation in shoots of plants. Plant Physiol. 2008, 146, 1673-1686. [CrossRef]

22. Bournier, M.; Tissot, N.; Mari, S.; Boucherez, J.; Lacombe, E.; Briat, J.F.; Gaymard, F. Arabidopsis ferritin 1 (AtFer1) gene regulation by the phosphate starvation response 1 (AtPHR1) transcription factor reveals a direct molecular link between iron and phosphate homeostasis. J. Biol. Chem. 2013, 288, 22670-22680. [CrossRef] [PubMed]

23. Lin, W.Y.; Huang, T.K.; Chiou, T.J. Nitrogen limitation adaptation, a target of microRNA827, mediates degradation of plasma membrane-localized phosphate transporters to maintain phosphate homeostasis in Arabidopsis. Plant Cell 2013, 25, 4061-4074. [CrossRef] [PubMed] 
24. Park, B.S.; Seo, J.S.; Chua, N.H. NITROGEN LIMITATION ADAPTATION recruits PHOSPHATE2 to target the phosphate transporter PT2 for degradation during the regulation of Arabidopsis phosphate homeostasis. Plant Cell 2014, 26, 454-464. [CrossRef]

25. Shin, H.; Shin, H.S.; Dewbre, G.R.; Harrison, M.J. Phosphate transport in Arabidopsis: Pht1; 1 and Pht1; 4 play a major role in phosphate acquisition from both low- and high-phosphate environments. Plant J. 2004, 39, 629-642. [CrossRef] [PubMed]

26. Ai, P.; Sun, S.; Zhao, J.; Fan, X.; Xin, W.; Guo, Q.; Yu, L.; Shen, Q.; Wu, P.; Miller, A.J.; et al. Two rice phosphate transporters, OsPht $1 ; 2$ and OsPht1; 6, have different functions and kinetic properties in uptake and translocation. Plant J. 2009, 57, 798-809. [CrossRef]

27. Zhang, Y.J.; Lynch, J.P.; Brown, K.M. Ethylene and phosphorus availability have interacting yet distinct effects on root hair development. J. Exp. Bot. 2003, 54, 2351-2361. [CrossRef]

28. Kim, H.J.; Lynch, J.P.; Brown, K.M. Ethylene insensitivity impedes a subset of responses to phosphorus deficiency in tomato and petunia. Plant Cell Environ. 2008, 31, 1744-1755. [CrossRef]

29. Chacon-Lopez, A.; Ibarra-Laclette, E.; Sanchez-Calderon, L.; Gutierrez-Alanis, D.; Herrera-Estrella, L. Global expression pattern comparison between low phosphorus insensitive 4 and WT Arabidopsis reveals an important role of reactive oxygen species and jasmonic acid in the root tip response to phosphate starvation. Plant Signal. Behav. 2011, 6, 382-392. [CrossRef] [PubMed]

30. Thibaud, M.C.; Arrighi, J.F.; Bayle, V.; Chiarenza, S.; Creff, A.; Bustos, R.; Paz-Ares, J.; Poirier, Y.; Nussaume, L. Dissection of local and systemic transcriptional responses to phosphate starvation in Arabidopsis. Plant J. 2010, 64, 775-789. [CrossRef]

31. Borch, K.; Bouma, T.J.; Lynch, J.P.; Brown, K.M. Ethylene: A regulator of root architectural responses to soil phosphorus availability. Plant Cell Environ. 1999, 22, 425-431. [CrossRef]

32. Swarup, R.; Perry, P.; Hagenbeek, D.; Van Der Straeten, D.; Beemster, G.T.; Sandberg, G.; Bhalerao, R.; Ljung, K.; Bennett, M.J. Ethylene upregulates auxin biosynthesis in Arabidopsis seedlings to enhance inhibition of root cell elongation. Plant Cell 2007, 19, 2186-2196. [CrossRef] [PubMed]

33. Stepanova, A.N.; Yun, J.; Likhacheva, A.V.; Alonso, J.M. Multilevel interactions between ethylene and auxin in Arabidopsis roots. Plant Cell 2007, 19, 2169-2185. [CrossRef] [PubMed]

34. Ruzicka, K.; Ljung, K.; Vanneste, S.; Podhorska, R.; Beeckman, T.; Friml, J.; Benkova, E. Ethylene regulates root growth through effects on auxin biosynthesis and transport-dependent auxin distribution. Plant Cell 2007, 19, 2197-2212. [CrossRef] [PubMed]

35. Qin, H.; Zhang, Z.; Wang, J.; Chen, X.; Wei, P.; Huang, R. The activation of OsEIL1 on YUC8 transcription and auxin biosynthesis is required for ethylene-inhibited root elongation in rice early seedling development. PLoS Genet. 2017, 13, e1006955. [CrossRef] [PubMed]

36. Werner, T.; Motyka, V.; Laucou, V.; Smets, R.; Van Onckelen, H.; Schmulling, T. Cytokinin-deficient transgenic Arabidopsis plants show multiple developmental alterations indicating opposite functions of cytokinins in the regulation of shoot and root meristem activity. Plant Cell 2003, 15, 2532-2550. [CrossRef]

37. Lai, F.; Thacker, J.; Li, Y.; Doerner, P. Cell division activity determines the magnitude of phosphate starvation responses in Arabidopsis. Plant J. 2007, 50, 545-556. [CrossRef]

38. Martin, A.C.; del Pozo, J.C.; Iglesias, J.; Rubio, V.; Solano, R.; de la Pena, A.; Leyva, A.; Paz-Ares, J. Influence of cytokinins on the expression of phosphate starvation responsive genes in Arabidopsis. Plant J. 2000, 24, 559-567. [CrossRef]

39. Kuiper, D.; Schuit, J.; Kuiper, P.J. Effects of internal and external cytokinin concentrations on root growth and shoot to root ratio of Plantago major ssp pleiosperma at different nutrient conditions. In Structural and Functional Aspects of Transport in Roots; Springer: Dordrecht, The Netherlands, 1989; pp. 183-188.

40. Franco-Zorrilla, J.M.; Martin, A.C.; Solano, R.; Rubio, V.; Leyva, A.; Paz-Ares, J. Mutations at CRE1 impair cytokinin-induced repression of phosphate starvation responses in Arabidopsis. Plant J. 2002, 32, 353-360. [CrossRef]

41. Nordstrom, A.; Tarkowski, P.; Tarkowska, D.; Norbaek, R.; Astot, C.; Dolezal, K.; Sandberg, G. Auxin regulation of cytokinin biosynthesis in Arabidopsis thaliana: A factor of potential importance for auxin-cytokinin-regulated development. Proc. Natl. Acad. Sci. USA 2004, 101, 8039-8044. [CrossRef]

42. Laplaze, L.; Benkova, E.; Casimiro, I.; Maes, L.; Vanneste, S.; Swarup, R.; Weijers, D.; Calvo, V.; Parizot, B.; Herrera-Rodriguez, M.B.; et al. Cytokinins act directly on lateral root founder cells to inhibit root initiation. Plant Cell 2007, 19, 3889-3900. [CrossRef] 
43. Singh, A.P.; Fridman, Y.; Holland, N.; Ackerman-Lavert, M.; Zananiri, R.; Jaillais, Y.; Henn, A.; Savaldi-Goldstein, S. Interdependent nutrient availability and steroid hormone signals facilitate root growth plasticity. Dev. Cell 2018, 46, 59-72.e4. [CrossRef] [PubMed]

44. Coudert, Y.; Perin, C.; Courtois, B.; Khong, N.G.; Gantet, P. Genetic control of root development in rice, the model cereal. Trends Plant Sci. 2010, 15, 219-226. [CrossRef] [PubMed]

45. Osmont, K.S.; Sibout, R.; Hardtke, C.S. Hidden branches: Developments in root system architecture. Annu. Rev. Plant Biol. 2007, 58, 93-113. [CrossRef] [PubMed]

46. Jobbagy, E.G.; Jackson, R.B. The distribution of soil nutrients with depth: Global patterns and the imprint of plants. Biogeochemistry 2001, 53, 51-77. [CrossRef]

47. Lynch, J.P.; Brown, K.M. Topsoil foraging-An architectural adaptation of plants to low phosphorus availability. Plant Soil 2001, 237, 225-237. [CrossRef]

48. Zhu, J.M.; Kaeppler, S.M.; Lynch, J.P. Topsoil foraging and phosphorus acquisition efficiency in maize (Zea mays). Funct. Plant Biol. 2005, 32, 749-762. [CrossRef] [PubMed]

49. Zhang, Z.; Zhang, Y.; Tan, H.; Wang, Y.; Li, G.; Liang, W.; Yuan, Z.; Hu, J.; Ren, H.; Zhang, D. RICE MORPHOLOGY DETERMINANT encodes the type II formin FH5 and regulates rice morphogenesis. Plant Cell 2011, 23, 681-700. [CrossRef]

50. Svistoonoff, S.; Creff, A.; Reymond, M.; Sigoillot-Claude, C.; Ricaud, L.; Blanchet, A.; Nussaume, L.; Desnos, T. Root tip contact with low-phosphate media reprograms plant root architecture. Nat. Genet. 2007, 39, 792-796. [CrossRef]

51. Pan, W.; Wu, Y.; Xie, Q. Regulation of ubiquitination is central to the phosphate starvation response. Trends Plant Sci. 2019, 24, 755-769. [CrossRef]

52. Rojas-Triana, M.; Bustos, R.; Espinosa-Ruiz, A.; Prat, S.; Paz-Ares, J.; Rubio, V. Roles of ubiquitination in the control of phosphate starvation responses in plants. J. Integr. Plant Biol. 2013, 55, 40-53. [CrossRef]

53. Ulrich, H.D. Mutual interactions between the SUMO and ubiquitin systems: A plea of no contest. Trends Cell Biol. 2005, 15, 525-532. [CrossRef] [PubMed]

54. Hershko, A.; Ciechanover, A. The ubiquitin system. Annu. Rev. Biochem. 1998, 67, 425-479. [CrossRef] [PubMed]

55. Leitner, J.; Petrasek, J.; Tomanov, K.; Retzer, K.; Parezova, M.; Korbei, B.; Bachmair, A.; Zazimalova, E.; Luschnig, C. Lysine63-linked ubiquitylation of PIN2 auxin carrier protein governs hormonally controlled adaptation of Arabidopsis root growth. Proc. Natl. Acad. Sci. USA 2012, 109, 8322-8327. [CrossRef] [PubMed]

56. Kumar, M.; Pandya-Kumar, N.; Dam, A.; Haor, H.; Mayzlish-Gati, E.; Belausov, E.; Wininger, S.; Abu-Abied, M.; McErlean, C.S.; Bromhead, L.J.; et al. Arabidopsis response to low-phosphate conditions includes active changes in actin filaments and PIN2 polarization and is dependent on strigolactone signalling. J. Exp. Bot. 2015, 66, 1499-1510. [CrossRef] [PubMed]

57. Bayle, V.; Arrighi, J.F.; Creff, A.; Nespoulous, C.; Vialaret, J.; Rossignol, M.; Gonzalez, E.; Paz-Ares, J.; Nussaume, L. Arabidopsis thaliana high-affinity phosphate transporters exhibit multiple levels of posttranslational regulation. Plant Cell 2011, 23, 1523-1535. [CrossRef]

58. Huang, T.K.; Han, C.L.; Lin, S.I.; Chen, Y.J.; Tsai, Y.C.; Chen, Y.R.; Chen, J.W.; Lin, W.Y.; Chen, P.M.; Liu, T.Y.; et al. Identification of downstream components of ubiquitin-conjugating enzyme PHOSPHATE2 by quantitative membrane proteomics in Arabidopsis roots. Plant Cell 2013, 25, 4044-4060. [CrossRef]

59. Yue, W.; Ying, Y.; Wang, C.; Zhao, Y.; Dong, C.; Whelan, J.; Shou, H. OsNLA1, a RING-type ubiquitin ligase, maintains phosphate homeostasis in Oryza sativa via degradation of phosphate transporters. Plant J. 2017, 90, 1040-1051. [CrossRef]

60. Wang, Z.; Ruan, W.; Shi, J.; Zhang, L.; Xiang, D.; Yang, C.; Li, C.; Wu, Z.; Liu, Y.; Yu, Y.; et al. Rice SPX1 and SPX2 inhibit phosphate starvation responses through interacting with PHR2 in a phosphate-dependent manner. Proc. Natl. Acad. Sci. USA 2014, 111, 14953-14958. [CrossRef]

61. Secco, D.; Wang, C.; Arpat, B.A.; Wang, Z.; Poirier, Y.; Tyerman, S.D.; Wu, P.; Shou, H.; Whelan, J. The emerging importance of the SPX domain-containing proteins in phosphate homeostasis. New Phytol. 2012, 193, 842-851. [CrossRef]

62. Yates, G.; Srivastava, A.K.; Sadanandom, A. SUMO proteases: Uncovering the roles of deSUMOylation in plants. J. Exp. Bot. 2016, 67, 2541-2548. [CrossRef] 
63. Miura, K.; Rus, A.; Sharkhuu, A.; Yokoi, S.; Karthikeyan, A.S.; Raghothama, K.G.; Baek, D.; Koo, Y.D.; Jin, J.B.; Bressan, R.A.; et al. The Arabidopsis SUMO E3 ligase SIZ1 controls phosphate deficiency responses. Proc. Natl. Acad. Sci. USA 2005, 102, 7760-7765. [CrossRef]

64. Miller, M.J.; Barrett-Wilt, G.A.; Hua, Z.; Vierstra, R.D. Proteomic analyses identify a diverse array of nuclear processes affected by small ubiquitin-like modifier conjugation in Arabidopsis. Proc. Natl. Acad. Sci. USA 2010, 107, 16512-16517. [CrossRef] [PubMed]

65. Huang, L.; Yang, S.; Zhang, S.; Liu, M.; Lai, J.; Qi, Y.; Shi, S.; Wang, J.; Wang, Y.; Xie, Q.; et al. The Arabidopsis SUMO E3 ligase AtMMS21, a homologue of NSE2/MMS21, regulates cell proliferation in the root. Plant J. 2009, 60, 666-678. [CrossRef] [PubMed]

66. Wang, L.; Lu, S.; Zhang, Y.; Li, Z.; Du, X.; Liu, D. Comparative genetic analysis of Arabidopsis purple acid phosphatases AtPAP10, AtPAP12, and AtPAP26 provides new insights into their roles in plant adaptation to phosphate deprivation. J. Integr. Plant Biol. 2014, 56, 299-314. [CrossRef] [PubMed]

67. Zhang, Y.; Wang, X.Y.; Lu, S.; Liu, D. A major root-associated acid phosphatase in Arabidopsis, AtPAP10, is regulated by both local and systemic signals under phosphate starvation. J. Exp. Bot. 2014, 65, 6577-6588. [CrossRef] [PubMed]

68. Wang, W.; Mauleon, R.; Hu, Z.; Chebotarov, D.; Tai, S.; Wu, Z.; Li, M.; Zheng, T.; Fuentes, R.R.; Zhang, F.; et al. Genomic variation in 3,010 diverse accessions of Asian cultivated rice. Nature 2018, 557, 43-49. [CrossRef]

(C) 2020 by the authors. Licensee MDPI, Basel, Switzerland. This article is an open access article distributed under the terms and conditions of the Creative Commons Attribution (CC BY) license (http://creativecommons.org/licenses/by/4.0/). 